\title{
Phase change-related variations of dome shape in \\ Eucalyptus urophylla x Eucalyptus grandis shoot apical meristems
}

François Mankessi ${ }^{1}$, Aubin R. Saya ${ }^{1}$, Frédéric Boudon ${ }^{2}$, Yann Guédon ${ }^{2}$, Fqbienne Montes ${ }^{3}$, Marc Lartaud ${ }^{3}$, Jean-Luc Verdeil ${ }^{3}$ and Olivier Monteuuis ${ }^{4}$

${ }^{1}$ UR2PI, B.P 1291 Pointe-Noire, Congo.

${ }^{2}$ CIRAD-BIOS, UMR DAP 1098 and INRIA, Virtual Plants, TA A-96/02, Avenue Agropolis, 34398 Montpellier, Cedex 5 France.

${ }^{3}$ CIRAD-BIOS, UMR DAP 1098 PHIV, TA 40/02, Avenue Agropolis, 34398 Montpellier, Cedex 5 France.

${ }^{4}$ CIRAD-BIOS, UMR DAP 1098, TA A-96/03, Avenue Agropolis 34398 Montpellier Cedex 5 France

Corresponding author: Olivier Monteuuis

CIRAD-BIOS, UMR DAP 1098,

TA A-96/03, Avenue Agropolis

34398 Montpellier, Cedex 5 FRANCE

Tel: $33(0) 467617121$

Fax: 33 (0)4 67615605

E-mail : olivier.monteuuis@cirad.fr 
Abstract Shoot apical meristem (SAM) domes derived from five different outdoor and in vitro sources of juvenile and mature Eucalyptus urophylla $\mathrm{x}$ Eucalyptus grandis akin genotypes were compared. Overall measurements of SAM dome height $\mathrm{H}$ and diameter $\mathrm{D}$ ranged from 2 to $35 \mu \mathrm{m}$ and 20 to $80 \mu \mathrm{m}$, notwithstanding significant differences according to the various physiological origins of plant material investigated. SAM domes from the mature trees "Mat" were taller than those from the rejuvenated ministock plants "Rej"; from the in vitro microcuttings "IVM" of the same clone, and also from the in vitro juvenile seedlings "IVJ", whereas outdoor seedlings "Juv" SAM domes exhibited intermediate height. SAM domes from the rejuvenated material "Rej", from the in vitro mature "IVM" and juvenile "IVJ" origins were also narrower than those from the outdoor seedlings "Juv" and to lesser extent than those from the mature trees "Mat". Overall the mature source "Mat" displayed bigger and somehow sharper hemispherical domes than those from "Rej" and "Juv", physiologically more juvenile, or those from the in vitro origins "IVM " and "IVJ" which looked flatter and smaller. SAM dome height, diameter $D$ and $H / D$ values varied also significantly according to shoot apex status. More specifically, H, D and H/D SAM differences between the five origins were not significant when SAM were in their more organogenic stage, to become more salient as leaf structures started to elongate and to differentiate. This was particularly obvious for mature tree "Mat" SAM dome shapes which showed at this stage much higher $H / D$ values than the other SAM sources. Additionally, a shape index $S$ used for characterizing more accurately dome shape confirmed these trends. These observations provide additional arguments to the view that juvenility in trees become more and more time and space restricted as ageing increases in the course of time during the ontogenetical process, to be ultimately confined to the more organogenic phases of SAM, from which shoot characteristics derive.

Keywords: Cloning - In vitro - Juvenility - Maturation - Physiological ageing 


\section{Introduction}

As plants start developing from seed germination, they undergo successive maturational phases, which are classically and chronologically referred to as (i) the juvenile phase, (ii) the mature or adult phase starting with the formation of the reproductive organs, and (iii) the senescent phase, prelude to the death of the individual (Doorenbos 1965, Hackett 1980, 1985). These phases correspond to different stages of physiological ageing (Borchert 1976) and can be associated to various changes, whose intensity varies according to species, such as decline or even loss of ability for adventitious rooting and true-to-type cloning, production of flowers, modification of phyllotaxy or foliar morphology, this last trait being particularly noticeable in heteroblastic species (Schaffalitzky de Muckadell 1959; Doorenbos 1965; Chuck and Hake 2005). All this illustrates the so-called "phase change" phenomenon which takes place within the shoot apical meristem or "SAM" for short (Poethig 1990; 2003). It has focused a particular attention for a long time especially in tree species due to their huge size and long life span (Schaffalitzky de Muckadell 1959, Romberger 1963, Robinson and Wareing 1969). It must be kept in mind indeed that every above ground structure of a tree derive from the initial single shoot primary meristem at the apical pole of the zygotic embryos (Monteuuis 1989; Bowman and Eshed 2000). Through its indefinite organogenic capacities, this shoot apical meristem allows trees to develop according to their ontogenetical program, with their relevant morphological and anatomical characteristics (Sharma and Fletcher 2002; Weigle and Jürgens 2002) and even for certain genotypes, to be clonally propagated through several and theoretically unlimited successive generations of clonal offspring (Monteuuis 1989).

Shoot apical meristems have been studied for a long time and are abundantly described in the literature (Buvat 1955; Romberger 1963; Medford 1992). Their characteristics are liable to vary according to species, and also to their metabolic activity (Romberger 1963; Gifford and Corson 1971). For instance, during the resting period, SAM are usually sharper than during budbreak (Owston 1969; Owens and Molder 1973). 
However, and apart from the transition between the vegetative and the reproductive state (Nougarede 2001; Sharma and Fletcher 2002), phase change-related modifications of SAM morphological characteristics have been so far only little investigated in arborescent species.

The purpose of this study is to further investigate this topic by analyzing dome shapes of SAM from different physiological ages produced by Eucalyptus urophylla $\mathrm{X}$ Eucalyptus grandis akin genotypes. This plant material was chosen owing to its remarkable performances to produce high yield clonal plantations in Congo (Saya et al 2008). Another major reason of this choice is the unexpected paucity of general knowledge on Eucalyptus spp SAM, despite the importance of this genus for research and operational uses (Coppen 2002).

\section{Materials and methods}

Plant material origin

Dome shapes of Eucalyptus urophylla X Eucalyptus grandis shoot apical meristems from five different origins were compared. They originated from $1 \mathrm{~cm}$ long actively growing shoot apices collected in April 2008 from the five following distinct sources:

1. "Mat": shoots with alternate phyllotaxy from the periphery of the crown of a 8year-old and $35 \mathrm{~m}$ tall Eucalyptus urophylla X Eucalyptus grandis donor plant growing in the savannas surrounding Pointe-Noire, Republic of Congo. This individual bearing fruits and therefore physiologically mature (Hackett 1983) was produced initially by rooted cuttings from the genotype 18-147, which was 24 year old since seed germination (Saya et al. 2008).

2. "Rej": shoots with opposite decussate phyllotaxy produced by regularly hedged 2 year-old and 8 to $10 \mathrm{~cm}$ tall container-grown mini stock plants from the same 18-147 clone, physiologically rejuvenated and intensively managed as described in Saya et al (2008). 
3. "Juv": shoots with opposite decussate phyllotaxy produced by 3-month-old and $35 \mathrm{~cm}$ as average height seedlings derived from the same parents as the mature genotype 18-147, as such termed full-sib (White et al 2007), and growing in the same nursery conditions as (2). This category of plant material was considered as the juvenile control.

4. "IVM": microshoots of the same 18-147 clone propagated in vitro during 6 years by monthly subcultures in accordance with the procedure detailed in Mankessi et al (2009).

5. "IVJ": microshoots of "clone S" derived from the in vitro germination of a seed of the same cross as 18-147, like "Juv", and propagated during 1 year rigorously in the same conditions as for "IVM", as specified in Mankessi et al (2009).

\section{Preparation for microscopic observations}

Just after collection, the 5 to $10 \mathrm{~mm}$ long shoot apices of each origin of plant materials were fixed for $48 \mathrm{~h}$ in $100 \mathrm{mM}$ phosphate buffer at $\mathrm{pH} 7.2$, supplemented with $1 \%(\mathrm{v} / \mathrm{v})$ glutaraldehyde, $2 \%(\mathrm{v} / \mathrm{v})$ paraformaldehyde, $1 \%(\mathrm{w} / \mathrm{v})$ caffeine, at room temperature (Schwendiman et al. 1988). Dehydration and embedding in Technovit 7100 resin (Heraeus Kulzer) were performed according to manufacturer's recommendations. Longitudinal sections of the apices were cut at $2.5 \mu \mathrm{m}$ thick in series with glass knives using a Leica RM2065 rotary microtome. Collected sections were double stained according to Buffard-Morel et al. (1992). Briefly, polysaccharides were stained in dark pink with periodic acid Schiff (PAS) and soluble proteins were stained in blue with naphtol blue-black (Sigma ref. 70490). Sections were then mounted in mowiol. Slides were observed with a microscope Leica DM6000 (Leica, Germany) under bright field. Thirty median longitudinal sections were used for each of the five origins of plant material. Pictures were taken with a Retiga 2000R camera 
(QImaging Co.) and images were processed through Volocity 4.0.1 (Improvision, Lexington, MA, USA).

Data collection and processing

For each of these longitudinal sections, the height " $H$ " and the diameter " $D$ " of the apical dome, "H" were measured with the Image J software (Abramoff et al 2004). H corresponded to distance from the distal tip of the dome to an imaginary line running perpendicular to the longitudinal axis of the shoot and originating at the point of insertion of the highest visible primordium to determine $D$, as depicted in Fig.1.

The first approach consisted in comparing $H, D$ and the ratio $H / D$ of the 30 longitudinal median sections of each plant material origin. Then, distinction was made within each origin between apices producing foliar initia and elongating primordia, and the other less organogenic showing leaflets with differentiated vascular bundles up to the tip. These two within origin classes were referred to $\mathrm{C} 1$ and $\mathrm{C} 2$, respectively (Fig. 2).

The second step consisted in sampling each of the SAM dome outline defined previously in an orthonormal axis system by 170 to 180 couples of $(x, y)$ data using the Image J software (Abramoff et al 2004). SAM shape was classically pictured as a dome (Schüepp 1966). In addition to height $H$ and radius $R(R=D / 2)$, a shape index $S$ was estimated for a better characterization of the bulged aspect of the dome based on the following superellipse equation:

$$
\left(\frac{x}{R}\right)^{S}+\left(\frac{y}{H}\right)^{S}=1
$$

This approach was inspired by the work of Cescatti (1997) concerning crown shape of trees. With $S=2$, the shape is a classical ellipsis (and a circle if $H=R$ ). $S>1, S=1$ and $S<1$ correspond respectively to convex, flat and concave shapes. For each SAM, the superellipse parameters $\mathrm{R}, \mathrm{H}$ and $\mathrm{S}$ were estimated using the least square method (see Bates and Watts (1988) for a general reference about nonlinear regression). This was 
performed using the scientific library for Python, SciPy (SciPy, 2008). For each apex origin and developmental class ( $\mathrm{C} 1$ or $\mathrm{C} 2$ ), the median estimated shape (i.e the most central one within the group) was extracted on the basis of the ranking of the estimated shapes along regularly spaced directions originating from the dome centre.

The data recorded were statistically analysed by analysis of variance using the SAS software (SAS Institute, Inc. 2000) "proc GLM" programs. Results are expressed as means. Bonferoni test was used to differentiate means within significant treatments (Sokal and Rohlf 1995). The significance level $P$ of all the statistical tests was set at Po $=0.05$ (Sokal and Rohlf 1995).

\section{Results}

SAM domes of the $E$. urophylla $X E$. grandis experimental plant material ranged roughly from 2 to $35 \mu \mathrm{m}$ in height $\mathrm{H}$ for 20 to $80 \mu \mathrm{m}$ in basal diameter $\mathrm{D}$. The one-way analysis of variance showed that these data, and even more strongly the ratio $H / D$, varied significantly $(P=$ 0.0003 for $H, P=0.0068$ for $D$ and $P<0.0001$ for $H / D$ ) according to the different origins of plant material assessed, each origin being represented by 30 SAM regardless of their developmental stage. Overall, the SAM collected from the mature trees "Mat" were markedly taller than those from the "Rej", "IVM" and "IVJ" sources which did not exhibit significant differences in height, whereas "Juv" SAM showed intermediate height values (Fig. 3). "Rej", "IVM" and "IVJ" origins scored also the smaller SAM diameter average values, significantly lower than for the "Juv" SAM, whereas "Mat" SAM had an intermediate average width (Fig. 4). The $H / D$ ratio gave rise to a more definite ranking with significantly superior average values for the "Mat" SAM than for the four other origins which could not be statistically differentiated (Fig. 5). Overall, the mature material SAM looked sharper than their homologs from the physiologically younger "Rej" and "Juv" sources, or from tissue culture, "IVJ" and "IVM". The high values of the coefficients of variation and within-origin mean square resulting from the one-way analysis of variance for each of the three indicators assessed, and 
especially for $\mathrm{H}$, prompted us to refine the analysis by distinguishing within each of the five origins of plant materials the two developmental classes $\mathrm{C} 1$ and $\mathrm{C} 2$ defined previously.

In fact, SAM organogenic stage had a stronger influence than plant origin on height $\mathrm{H}$ $(P<0.0001$ versus $P=0.0034)$ and on diameter $D(P<0.0001$ versus $P=0.114)$, whereas these two factors had the same great impact on the ratio $H / D(P<0.0001)$. Regardless of plant origin, C2 SAM were on average taller $(16.2 \mu \mathrm{m}$ versus $2.7 \mu \mathrm{m})$, wider $(64.0 \mu \mathrm{m}$ versus $24.1 \mu \mathrm{m})$ and sharper as reflected by a higher $\mathrm{H} / \mathrm{D}$ ratio $(0.22$ versus 0.13$)$ than the $\mathrm{C} 1$ ones. These trends are illustrated in Fig. 6, 7 and 8 for each of the ten plant origin $\mathrm{X}$ developmental class combinations, which were found to influence significantly $H, D$ and $H / D$ values $(P<$ 0.0001). C2 SAM were markedly higher than C1 ones for the mature origin "Mat", and to lesser extent although still significantly for the juvenile seedlings "Juv" compared to the other origins (Fig. 6), consistently with the significant origin $X$ class interaction highlighted by the factorial analysis of variance for $H(P=0.0089)$. Except for the in vitro mature clone "IVM", the four plant material origins displayed noticeably wider SAM during C2 than C1 stages (Fig. 7). Regarding the $H I D$ scores, the superiority of mature material $C 2$ class over the other plant origin $\mathrm{X}$ class combinations was particularly noteworthy, as reflected by the significant interaction $(P=0.0128)$ highlighted by the factorial analysis of variance.

The median superellipse for the five origins of SAM grouping then distinguishing classes $\mathrm{C} 1$ and $\mathrm{C} 2$ are illustrated in Fig. 9, 10 and 11. Most of the coefficients of determination $\left(r^{2}\right)$ were superior to 0.80 . On average, $r^{2}$ values were higher for SAM in C1 than in $\mathrm{C} 2$ stage. The H, D and H/D deduced from the estimated superellipses were always close to the corresponding measured values. The shape index $S$ was not influenced by the plant material origin, but varied significantly according to developmental classes $\mathrm{C} 1$ and $\mathrm{C} 2$ $(P<0.0001)$ with a significant interaction $(P=0.0197)$ between these two factors. This accounts for the highly significant effect $(P<0.0001)$ of the ten different plant material origin $x$ class combinations on SAM shape index $S$ illustrated in Fig. 9. Higher scores for $\mathrm{C} 2$ than for the more organogenic $\mathrm{C} 1$ stage were found for the juvenile seedlings "Juv", the two in vitro sources, "IVM" and "IVJ" and the rejuvenated material "Rej" in absence of significant 
difference for this latter origin, although more obvious than for the mature material "Mat" (Fig. 9).

\section{Discussion}

Height and diameter as defined in our study have been commonly used for comparing SAM size and shape of tree species in different and contrasted physiological conditions (Gifford and Corson 1971). These were mostly conifers, dormant or metabolically active depending on the marked seasonal variations of the natural environment to which they were exposed. With respect to the species, the origin and age of the plant material used, and also to its growing conditions, our study looks objectively innovative. In the first place, E. urophylla X E. grandis SAM appeared to be overall smaller than in a lot of Gymnosperms and Angiosperms (Clowes 1961), for which variations in size, shape and even inner cyto-histological organization have been observed according to species and even within species (Parke 1959; Owston and Molder 1973; Monteuuis 1989b). The influences of ageing and tissue culture conditions on such parameters have been until now only little investigated. Tepper (1963) in Pinus ponderosa noticed that SAM H/D ratio increased, mainly due to the reduction of the diameter D, as the lateral branches from which the apical meristems had been collected became older. In Pinus strobus, Owston (1968) observed the same trends but associated to a marked increment in height. In Sequoiadendron giganteum during the resting period (Monteuuis 1987; 1988; 1989b), $\mathrm{H}$ and H/D values were higher for SAM from 100 year-old grafted plants than from 18 month-old seedlings, confirming that SAM shape varies with chronological, ontogenetical and physiological ageing, as defined by Fortanier and Jonkers (1976). The current findings provides additional arguments to this statement, the SAM from the juvenile seedlings "Juv" being chronologically, ontogenetically and physiologically younger than those collected from the upper part of the crown of the mature trees "Mat". We decided to use as juvenile control "Juv" seedlings derived from the same parents as the mature genotype $18-147$ in order to minimise the risks of genetic bias on our age-related SAM morphological investigations. This seems very unlikely considering the similarities 
previously reported existing for the same criteria between species genetically far distant from one another. More interesting and original are the differences pointed out for SAM H/D between the mature and the other origins, including the rejuvenated line of the same genotype. These observations at the SAM level follow the same trend as the capacity for true to type cloning by rooted cuttings (Saya et al 2008): the physiologically rejuvenated clonal offspring of the mature genotype "Rej" and the juvenile material "Juv" demonstrated identical characteristics, by contrast with the physiologically more mature origin "Mat". The physiological rejuvenation observed for the mature material at the macroscopic level is also obvious for SAM outlines.

$\mathrm{H}$ and $\mathrm{D}$ measurements tend to indicate that SAM of tissue cultured plant material are overall smaller than that of their juvenile "Juv", rejuvenated "Rej" and mature "Mat" outdoor homologs. This observation, strengthened by the best-fit superellipses, is consistent with the results of Watelet-Gonod and Favre (1981) concerning Dahlia variabilis.

Metabolic and organogenic activities have been identified as the main cause of SAM variations in shape, in close relationship with seasonal changes for species growing naturally in temperate environment (Parke 1959; Owston 1969; Monteuuis 1987). In Pointe Noire outdoor conditions, shoots keep on growing continuously even at a slower rate during the drier periods. There was therefore no obvious macroscopic indicator to sort out plant material samples according to SAM organogenic stage at the collection time, and likewise for the tissue cultured material, notwithstanding possible rhythmic growth and endogenous rhythm influence (Barthelemy and Caraglio 2007; Mankessi et al 2009). This accounted for the great within sample variations noticed in the first approach. Distinguishing a posteriori within each sample class C1 and class C2 improved the significance of the statistical tests. For instance, the $H, D$ and $H / D$ SAM differences between the five origins found not significant for $C 1$ became particularly salient for less organogenic C2 SAM. In other words, there was no noticeable influence of ageing on SAM outlines during the more organogenic phase corresponding to initium formation, and the first steps of primordia elongation, contrary to what could be observed during the subsequent developmental phases C2. These 
observations on E. urophylla X E. grandis are consistent with previous observations on Sequoiadendron giganteum (Monteuuis 1987; 1988). They provide additional supportive arguments to the view that juvenile and mature trees can show "windows" of similarities more and more time and space restricted as ageing increases in the course of time during the ontogenetical process, to become ultimately restricted to the more organogenic phases of SAM (Krenke 1940; Monteuuis 1989a). Such similarities can be observed with regard to various aspects, as illustrated for SAM outlines by the current study. Our findings strengthen also the relationship between SAM and shoot characteristics (Schaffalitzky de Muckadell 1959; Weige and Jürgen 2002), emphasizing once again the importance SAM physiological ageing (Monteuuis 1989a; Barthelemy and Caraglio 2007), conceptually referred to as cyclophysis (Schaffalitzky de Muckadell 1959; Olesen 1978). As supported by numerous rejuvenation reports (Hackett 1985; Greenwood 1987; von Aderkas and Bonga 2000), this phenomenon is reversible and of overriding importance for adventitious rooting and true-totype cloning (Riding 1976; Monteuuis 1989a, 2004).

\section{References}

Abramoff MD, Magelhaes PJ, Ram SJ (2004) “Image Processing with ImageJ”. Biophotonics International, volume 11, issue 7, pp. 36-42,

Borchert R (1976) The concept of juvenilety in woody plants. Acta Hortic. 56:57-69.

Bowman JL, Eshed Y (2000) Formation and maintenance of the shoot apical meristem. Trends in plant science, 5(3): 110-115.

Barthelemy D, Caraglio Y (2007) Plant Architecture: A Dynamic, Multilevel and comprehensive approach to Plant Form, Structure and Ontogeny. Annals of Botany 99: 375-407.

Bates DM, Watts DG (1988) Nonlinear regression analysis and its applications, John Wiley \& Sons, New York Singapore, 365p

Buffard-Morel J, Verdeil JL, Pannetier C (1992): Embryogenèse somatique du cocotier (Cocos nucifera L.) à partir d'explant foliaire: étude histologique. Can J Bot 70: 735741.

Buvat R:(1955) Le méristème floral de la tige. Ann. Biol., $31:$ 596-656.

Chuck G, Hake S (2005) Regulation of developmental transitions. Current Opinion in Plant Biology, 8: 67-70.

Coppen JWJ (2002) Eucalyptus: the genus eucalyptus. Taylor and Francis, New York, 450p.

Cescatti A (1997) Modelling the radiative transfer in discontinuous canopies of asymmetric crown. I. model structure and algorithms, Ecological Modelling 101: 263274.

Doorenbos J (1965) Juvenile and adult phases in woody plants. Encycl. Plant. Physiol., 15 (1): 1222-1235. 
Fortanier EJ, Jonkers H (1976) Juvenility and maturity of plants as influenced by their ontogenetical and physiological ageing. Acta Hortic. 56:37-43.

Gifford EM, Corson GE (1971) The shoot apex in seed plant. The Botanical Review, 37 (2): 143-229.

Hackett WP (1980) Control of phase change in woody plants. In Proc. of the IUFRO joint workshop on "Control of shoot growth in trees, Fredericton, New Brunswick, Canada, 257-272.

Hackett WP (1985) Juvenility, maturation and rejuvenation in woody plants. Horticultural Reviews, 7:109-155.

Krenke NP (1940) The theory of the cycle of senescence and rejuvenation of plants and its practical application. Plant Breed. Abstract. 15: 1-135

Mankessi F, Saya A, Baptiste C, Nourissier S, Monteuuis O (2009) In vitro rooting of genetically related Eucalyptus urophylla $X$ Eucalyptus grandis clones in relation to the time spent in culture. Trees, 23, 931-940.

Medford JI (1992) Vegetative apical meristems. The Plant Cell, 4: 1029-1039.

Monteuuis O (1987) Profils méristématiques de séquoias géants (Sequoiadendron giganteum Buchholz) jeunes et âgés durant les stades de repos végétatif et de débourrement. C.R. Acad. Sc. Paris, 305, (III), 715-720.

Monteuuis O (1988) Aspects du clonage de séquoias géants jeunes et âgés. PhD thesis, Univ. Blaise Pascal, Clermont-Ferrand, 190p.

Monteuuis O (1989a) Maturation concept and possible rejuvenation of arborescent species. Limits and promises of shoot apical meristems to ensure successful cloning. In: "Breeding Tropical Trees: Population Structure and Genetic Improvement Strategies in Clonal and Seedling Forestry". Proc. Conference IUFRO, Pattaya, Thailand, 28 Nov.-3Dec. 1988, 106-118.

Monteuuis O (1989b) Analyses microscopiques de points végétatifs de Sequoiadendron giganteum jeunes et âgés durant le repos végétatif et lors du débourrement. Bull. Soc. Bot. Fr., 136, Lettres Bot. (4/5), 317-326.

Monteuuis $O$ (2004) In vitro rooting of juvenile and mature Acacia mangium microcuttings with reference to leaf morphology as a phase change marker. Trees, 18 (1), 77-82.

Nougarède $A$ (2001) Le méristème caulinaire des Angiospermes : nouveaux outils, nouvelles interprétations. Acta Bot. Gallica, 148 (1) : 3-77.

Olesen PO (1978) On cyclophysis and topophysis. Silvae Genetica. 27 (5) 173-178.

Owston PW (1969) The shoot apex in eastern white pine: its structure, seasonal development, and variation within the crown. Can. J. Bot. 47: 1181-1188.

Owston PW, Molder M (1973) Bud development in western hemlock. I. Annual growth cycle of vegetative buds. Can. J. Bot. 51: 2223-2231.

Parke RV (1959) Growth periodicity and the shoot tip of Abies concolor. Am. Jour. Bot, 46(2): 110-118.

Poethig RS (1990) Phase change and the regulation of shoot morphogenesis in plants. Science 250: 923-930.

Poethig RS (2003) Phase change and the regulation of developmental timing in plants. Science 301: 334-336.

Riding RT (1976) The shoot apex of trees of Picea mariana of differing rooting potential. Can. J. Bot. 54: 2672-2678.

Robinson LW, Wareing PF (1969) Experiments on the juvenile-adult phase change in some woody species. New Phytol. 68: 67-78.

Romberger JA (1963) Meristems: growth and development in woody plants. U.S. Dep. Agr. Tech. Bull. Ed, $214 \mathrm{p}$.

SAS (2000) SAS/STAT User's Guide, Cary, NC, USA.

Saya RA, Mankessi F, Toto M, Marien JN, Monteuuis O (2008) Advances in mass clonal propagation of Eucalyptus urophylla $X$ E. grandis in Congo. Bois et Forêts des Tropiques, 297: 15-25 
Schaffalitzky de Muckadell M (1959) Investigations on aging of apical meristems in woody plants and its importance in silviculture. Kandrup and Wunsch's Bogtrykkeri, København, pp 313-346.

SciPy (2008) Scientific Tools for Python, SciPy Reference Guide, Enthought, http://www.scipy.org.

Schüepp O (1966) Meristeme: Wachstum und Formbildung in den Teilungsgeweben höherer Pflanzen. Birkhäuser verlag, Basel and Stuttgart, 253p.

Schwendiman J, Pannetier C, Michaux-Ferriere N (1988) Histology of somatic embryogenesis from leaf explants of the oil palmElaeis guineensis. Ann Bot (Lond) 62:43-52

Sharma VK, Fletcher JC (2002): Maintenance of shoot and floral meristem cell proliferation and fate. Plant Physiol. 129: 31-39.

Sokal RR, Rohlf FJ (1995) Biometry. WH Freeman and Company, New York, USA, 887 pp.

von Aderkas P, Bonga JM (2000) Influencing micropropagation and somatic embryogenesis by manipulation of phase change and culture environment. Tree Physiol. 20: 921-928.

Watelet-Gonod MC, Favre JM (1981) Miniaturisation et rajeunissement chez Dahlia variabilis (variété Télévision) cultivé in vitro. Ann. Sci. Nat. Bot. 13 (2-3), 51-67.

Weigel D, Jürgen G (2002) Stem cells that make stems. Nature 415, 751-754. 


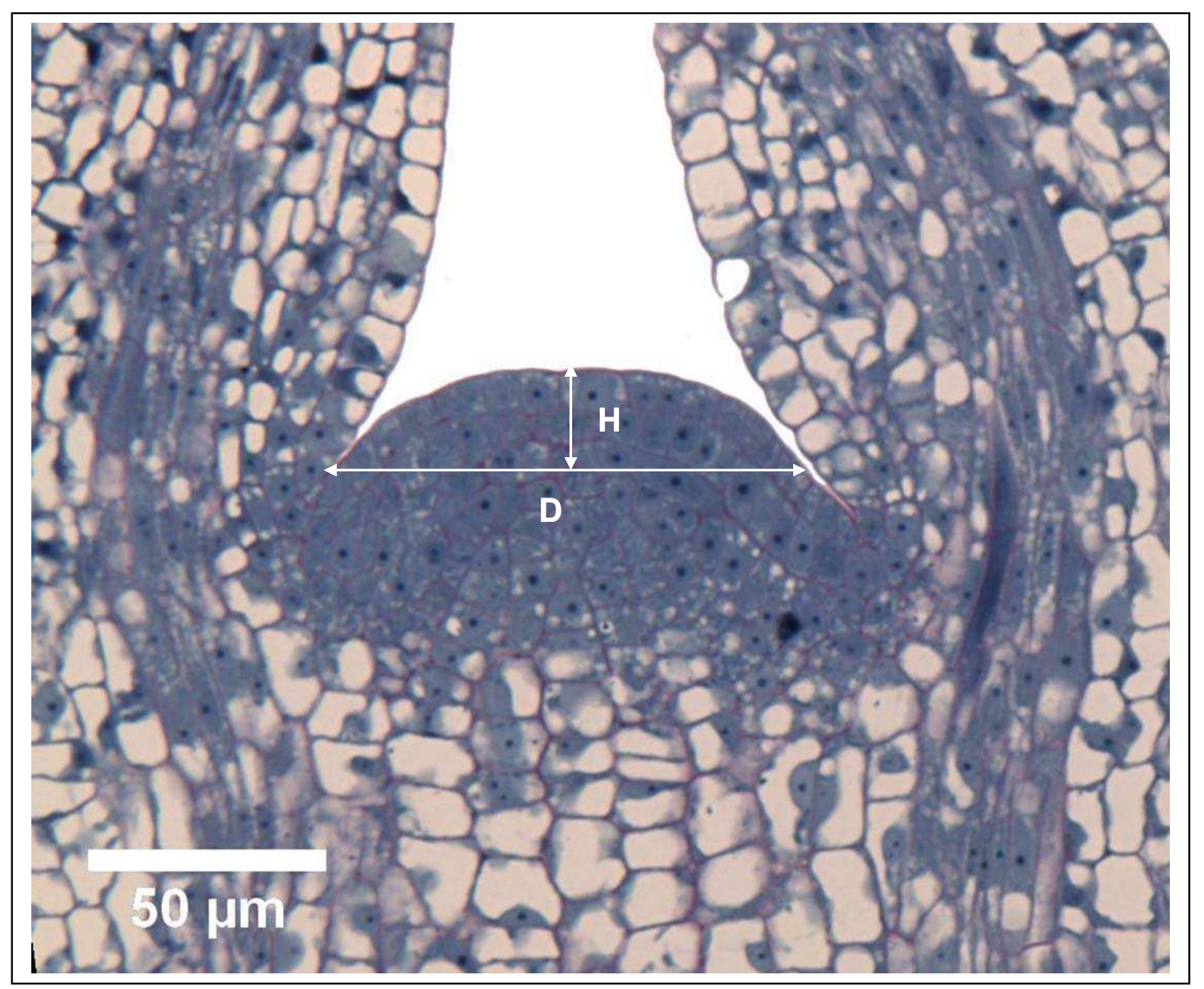

Fig. 1. Longitudinal median cross section of an E.urophylla $X$ E. grandis SAM illustrating how $H$ and $D$ were established. 
A inclure

A inclure

Fig. 2. Longitudinal median cross sections of E. urophylla X E. grandis SAM of class C1 (left) characterized by developing primordial, and of class $\mathrm{C} 2$ (right), less organogenic with elongating leaflets showing distinctly differentiated vascular bundles up to the tip. 


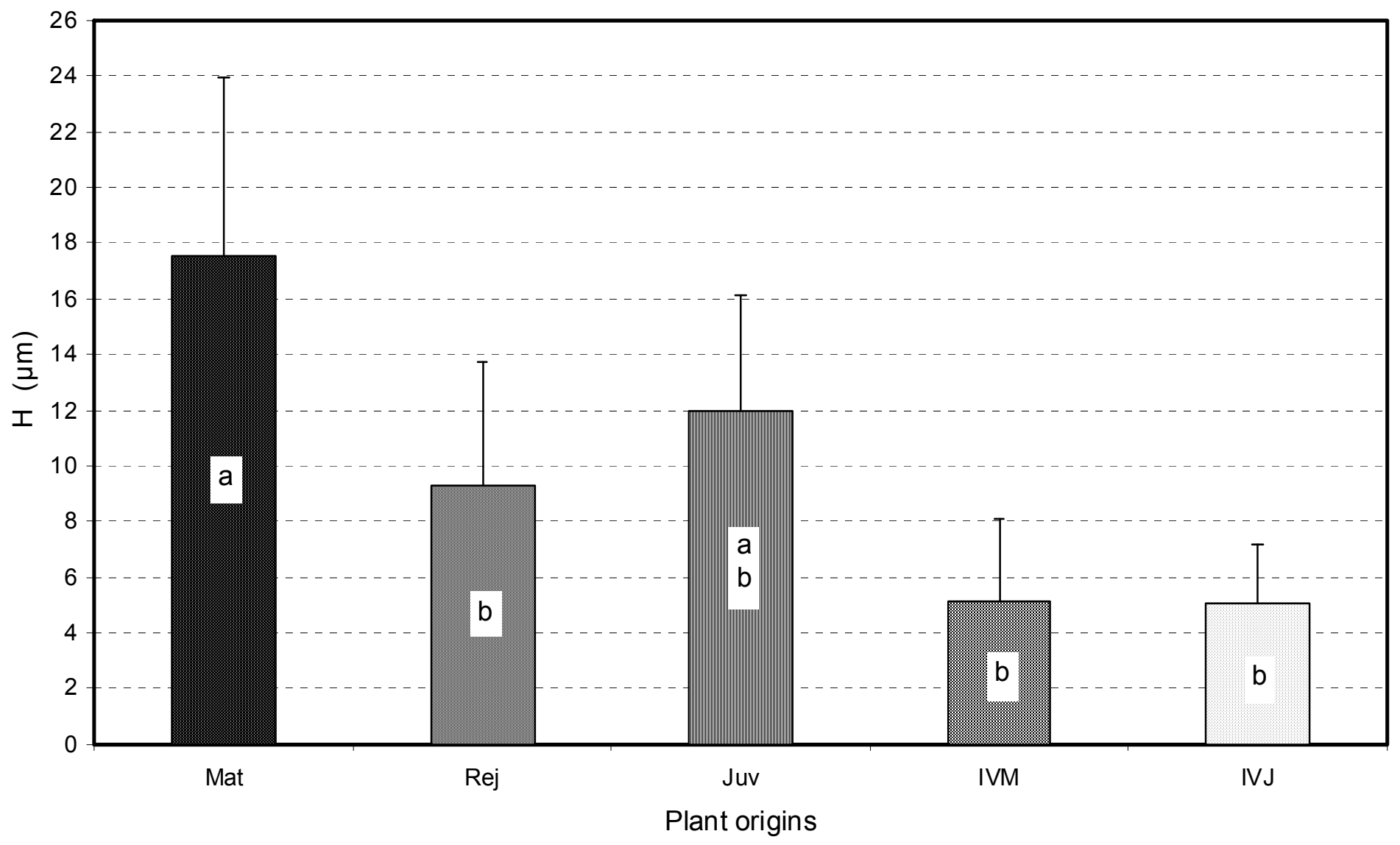

Fig. 3. Average dome heights $\mathrm{H}$ of the five SAM origins assessed. Mean values were established from 30 observations per origin. Bars represent confidence intervals at $\mathrm{Po}=5 \%$, and different letters distinguish means which are significantly different at the same $5 \%$ level (see text for further information). 


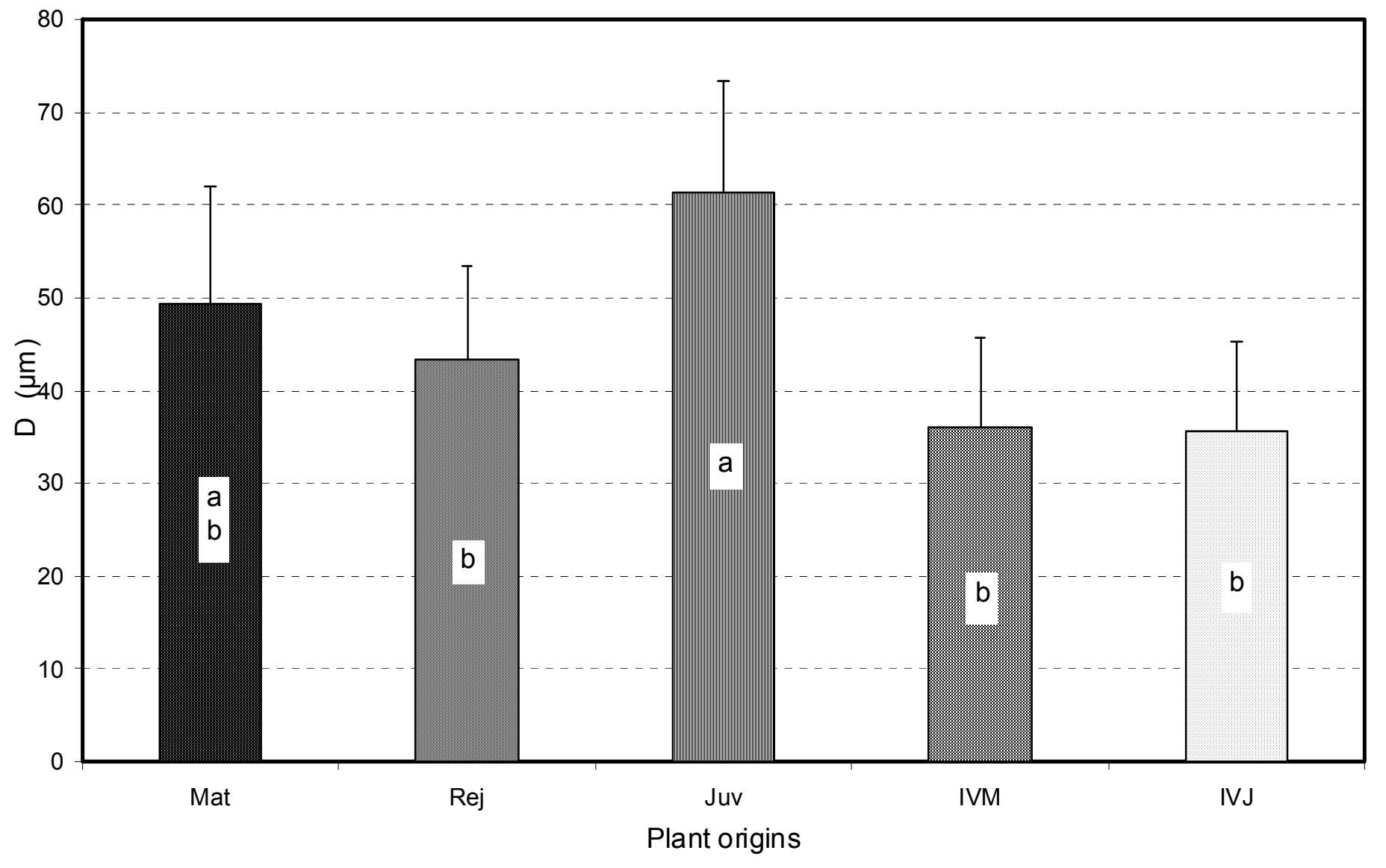

Fig. 4. Average dome basal diameters $D$ of the five SAM origins assessed. Mean values were established from 30 observations per origin. Bars represent confidence intervals at Po $=5 \%$, and different letters distinguish means which are significantly different at the same $5 \%$ level (see text for further information). 


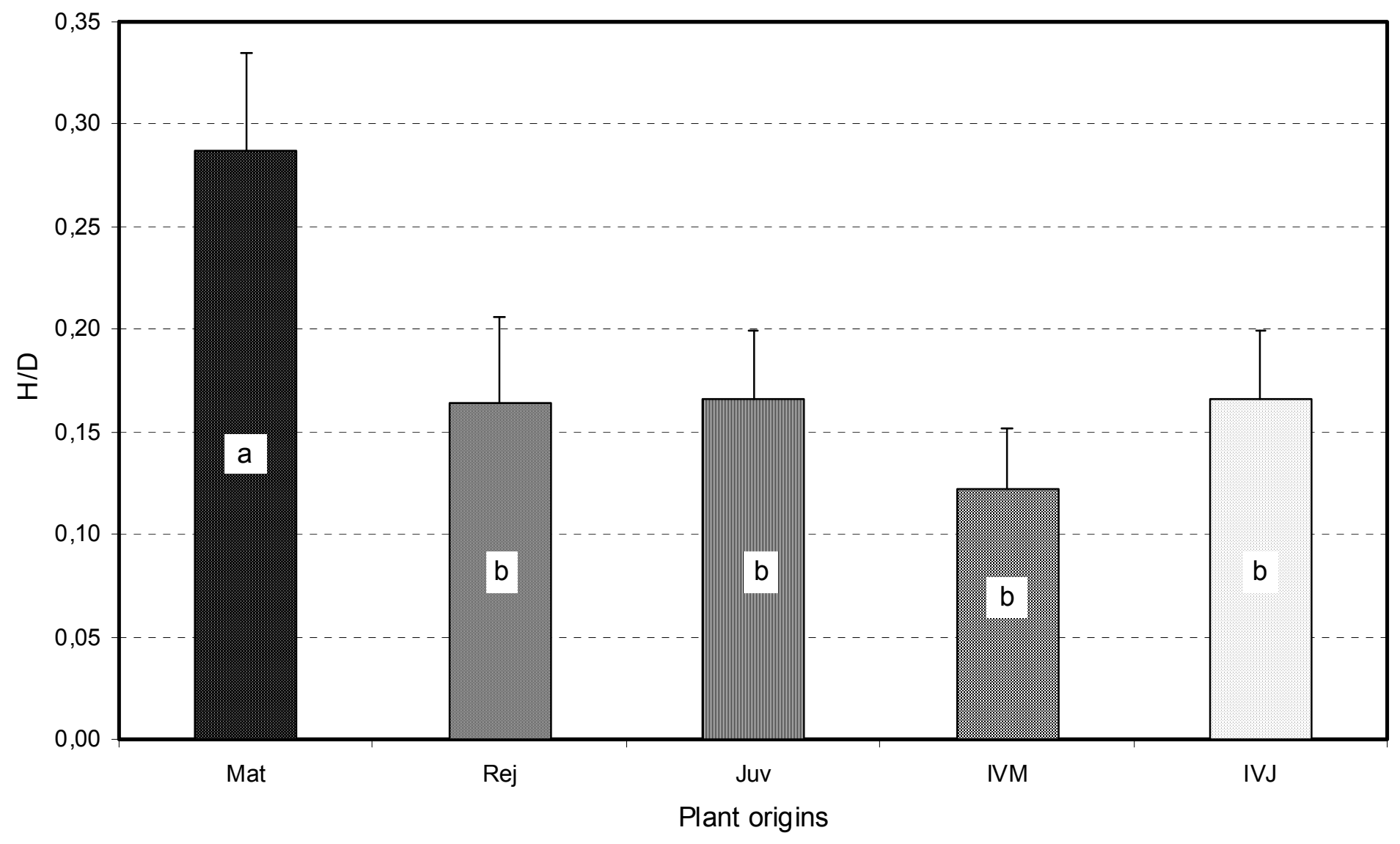

Fig. 5. Average $H / D$ values of $S A M$ domes for the five origins of plant material assessed. Mean values were established from 30 observations per origin. Bars represent confidence intervals at $\mathrm{Po}=5 \%$, and different letters distinguish means which are significantly different at the same $5 \%$ level (see text for further information). 


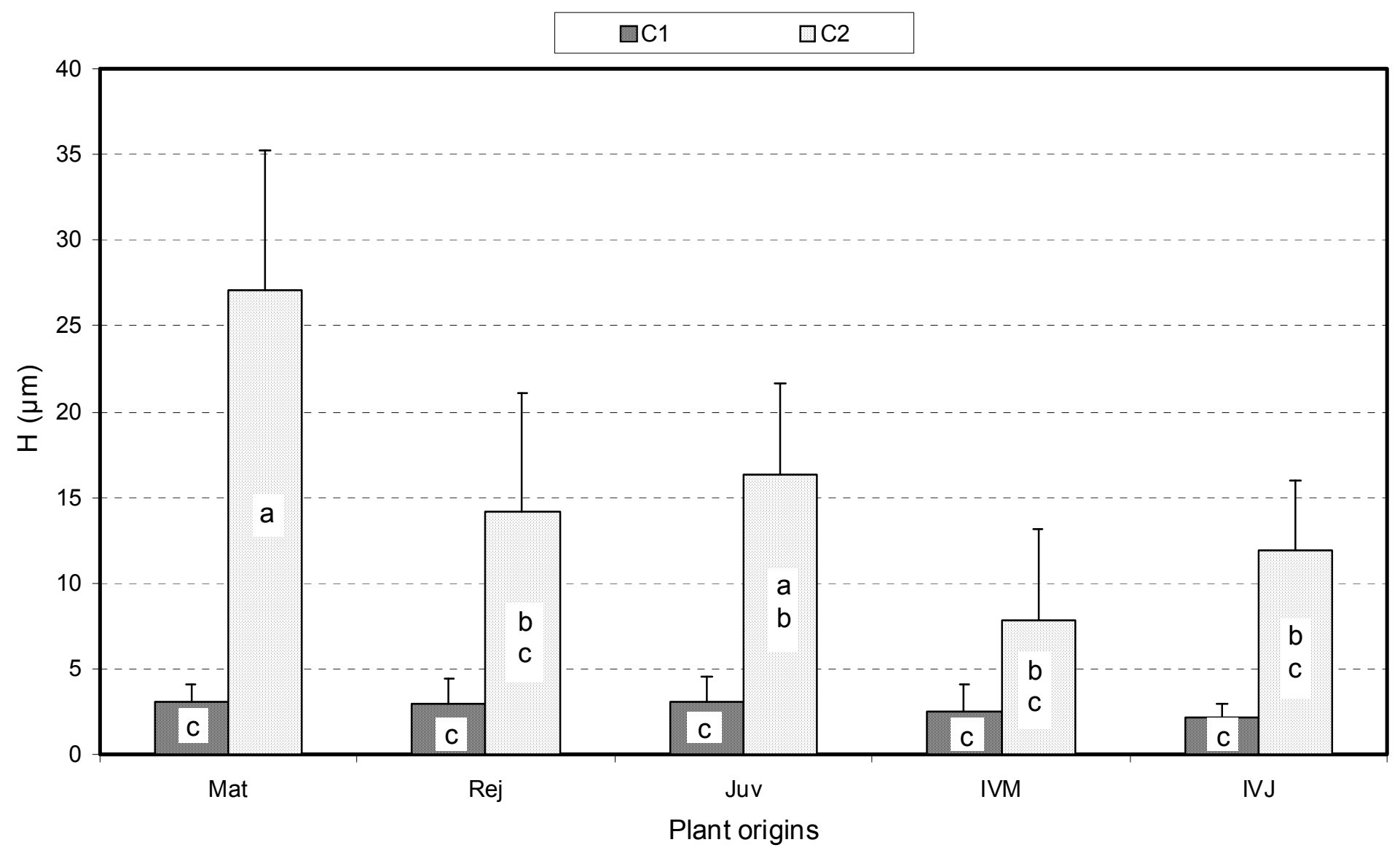

Fig. 6. Average SAM dome heights $\mathrm{H}$ for the ten plant origin $\mathrm{X}$ class combinations assessed. Mean values were established from 9 to 21 observations per combination. Bars represent confidence intervals at Po $=5 \%$, and different letters distinguish means which are significantly different at the same $5 \%$ level (see text for further information). 


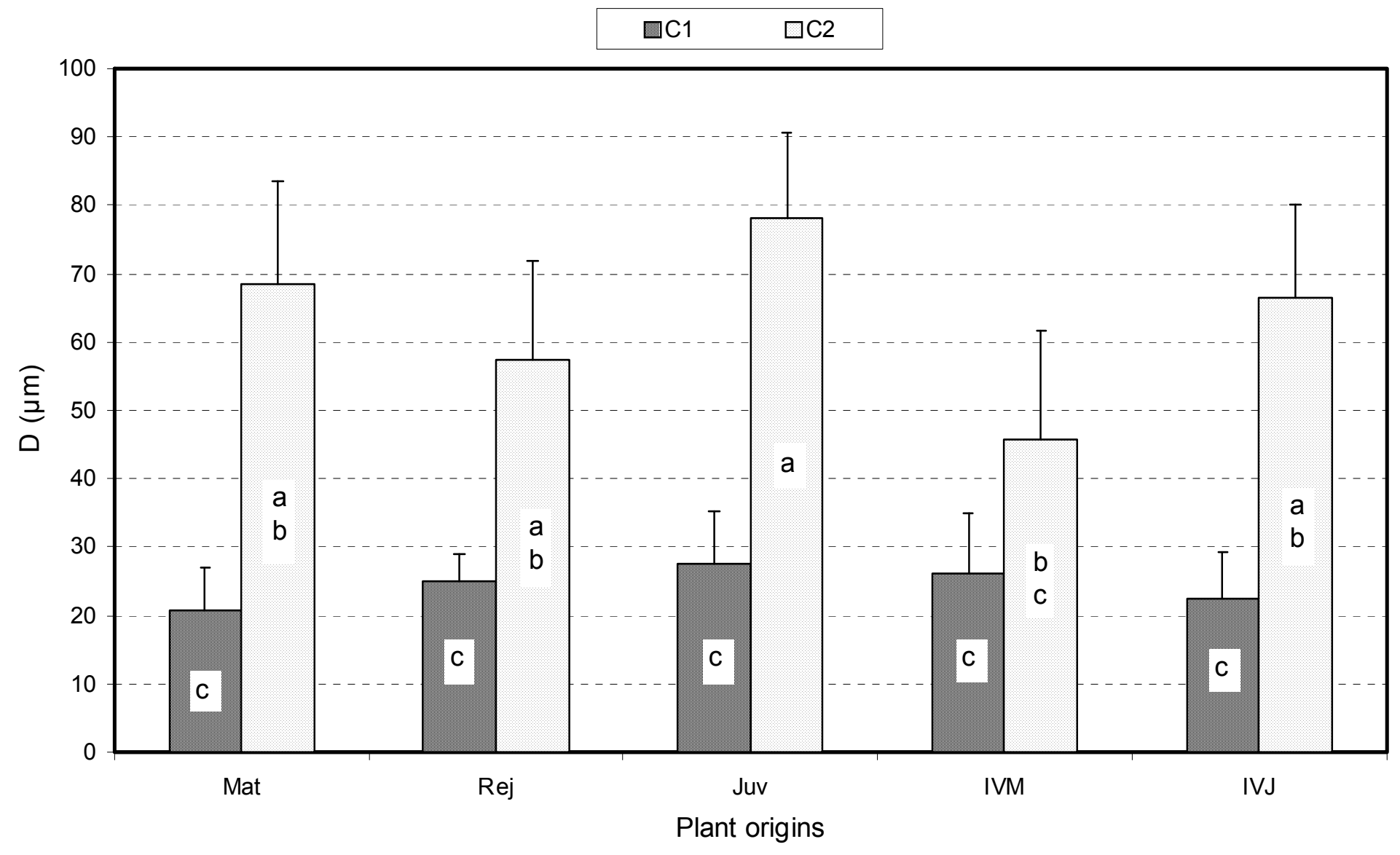

Fig. 7. Average SAM dome diameters $D$ for the ten plant origin $X$ class combinations assessed. Mean values were established from 9 to 21 observations per combination. Bars represent confidence intervals at Po $=5 \%$, and different letters distinguish means which are significantly different at the same $5 \%$ level (see text for further information). 


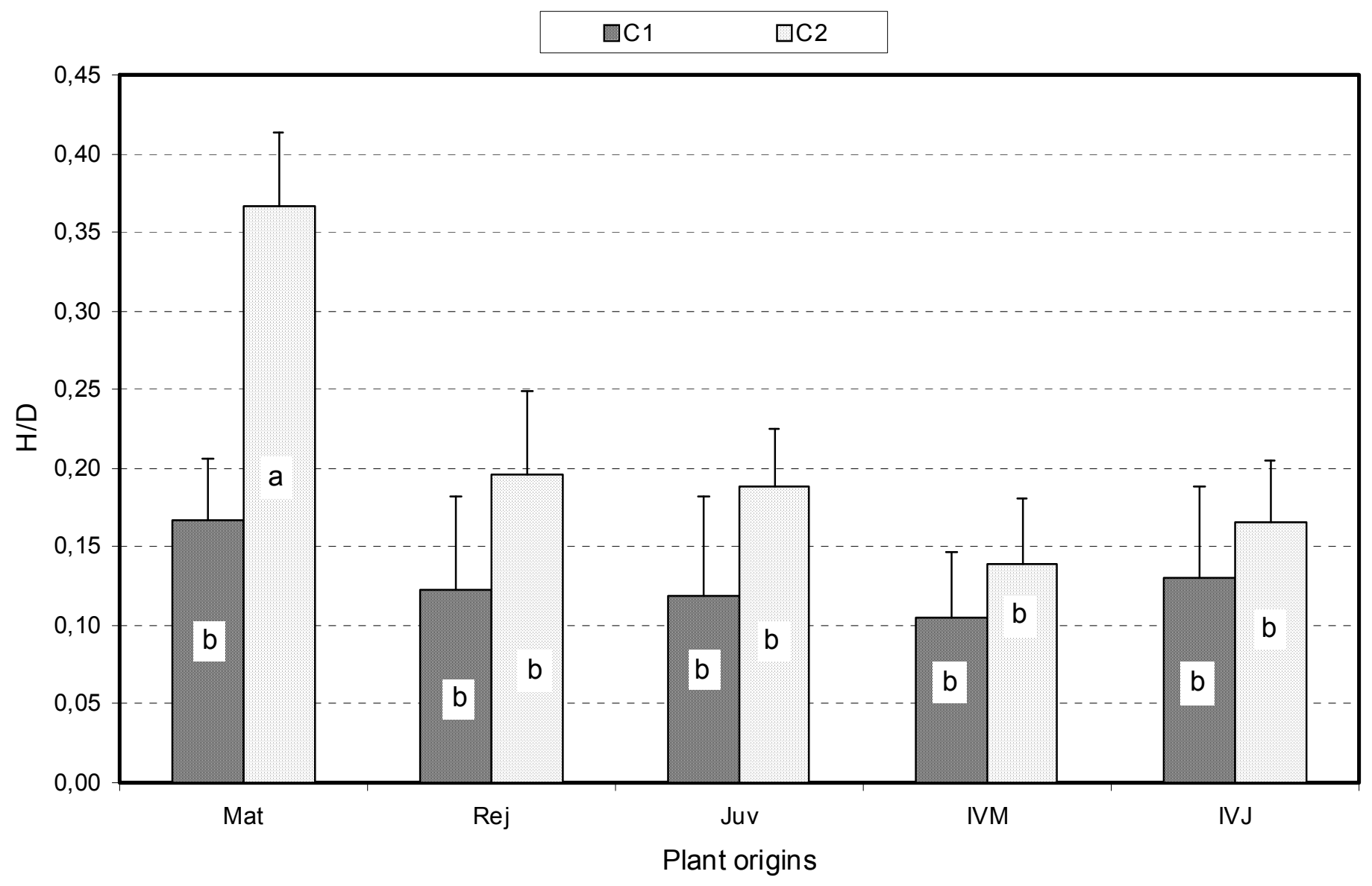

Fig. 8. Average SAM dome $H / D$ values for the ten plant origin $X$ class combinations assessed with 9 to 21 observations per combination. Bars represent confidence intervals at $\mathrm{Po}=5 \%$, and different letters distinguish means which are significantly different at the same $5 \%$ level (see text for further information). 


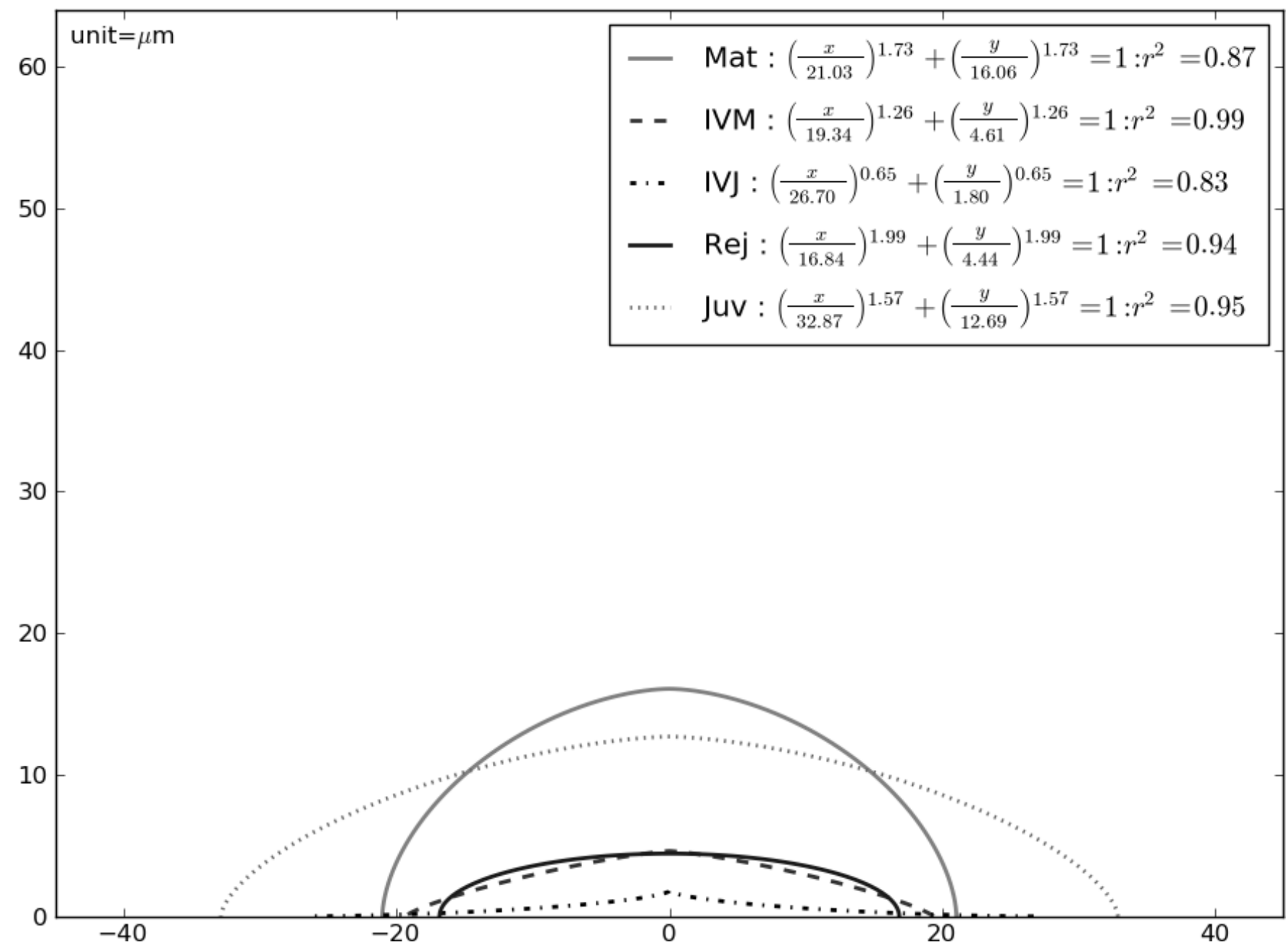

Fig. 9. Median estimated superellipse (sample size $N=30$ ) for the five origins of SAM assessed, with the associated equations and coefficients of determination $\left(r^{2}\right)$. 


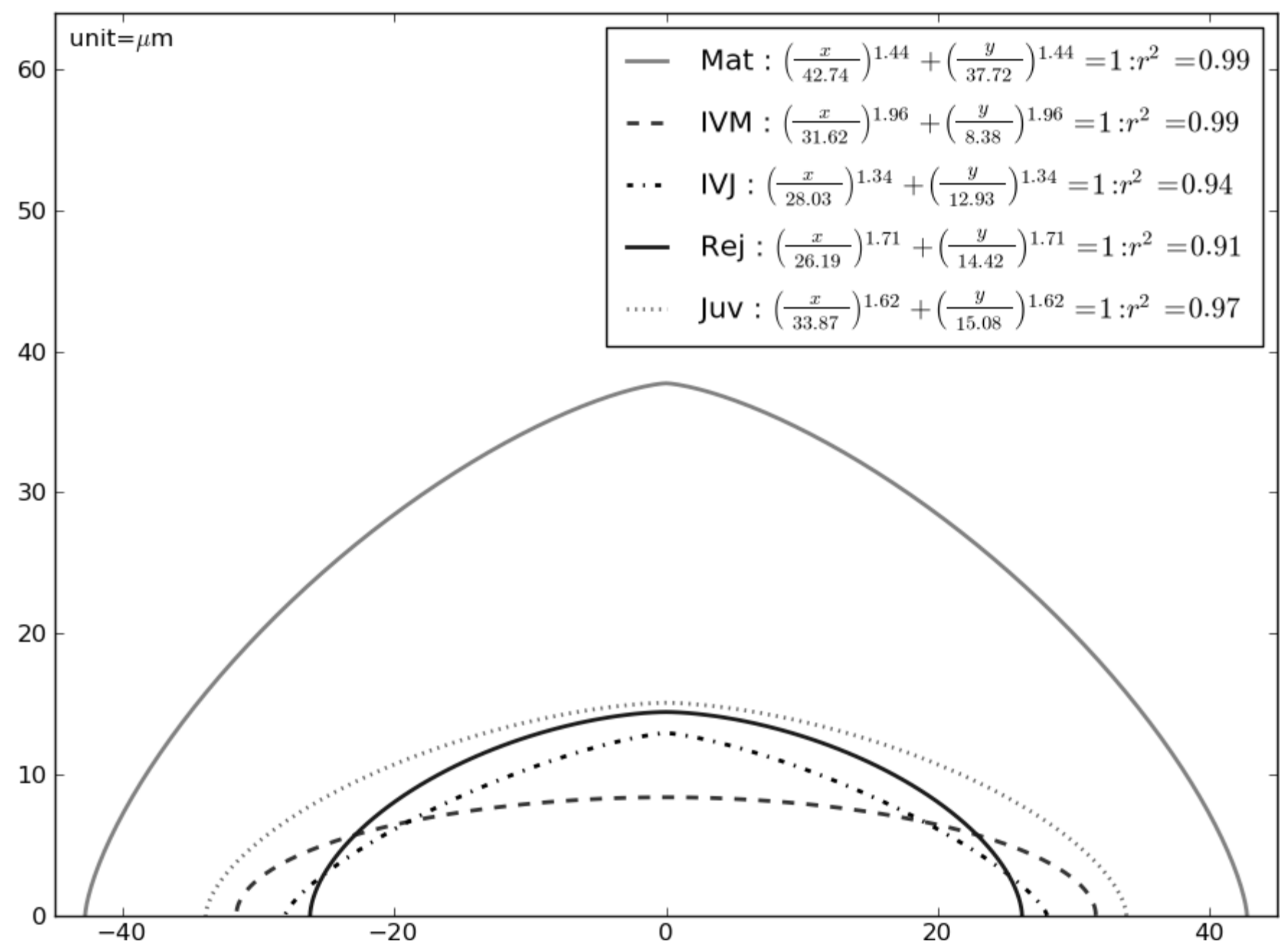

Fig. 10. Median estimated superellipse (sample size: $9 \leq \mathrm{N} \leq 21$ ) for the five origins of SAM assessed in $\mathrm{C} 1$ stage; with the associated equations and coefficients of determination $\left(r^{2}\right)$. 


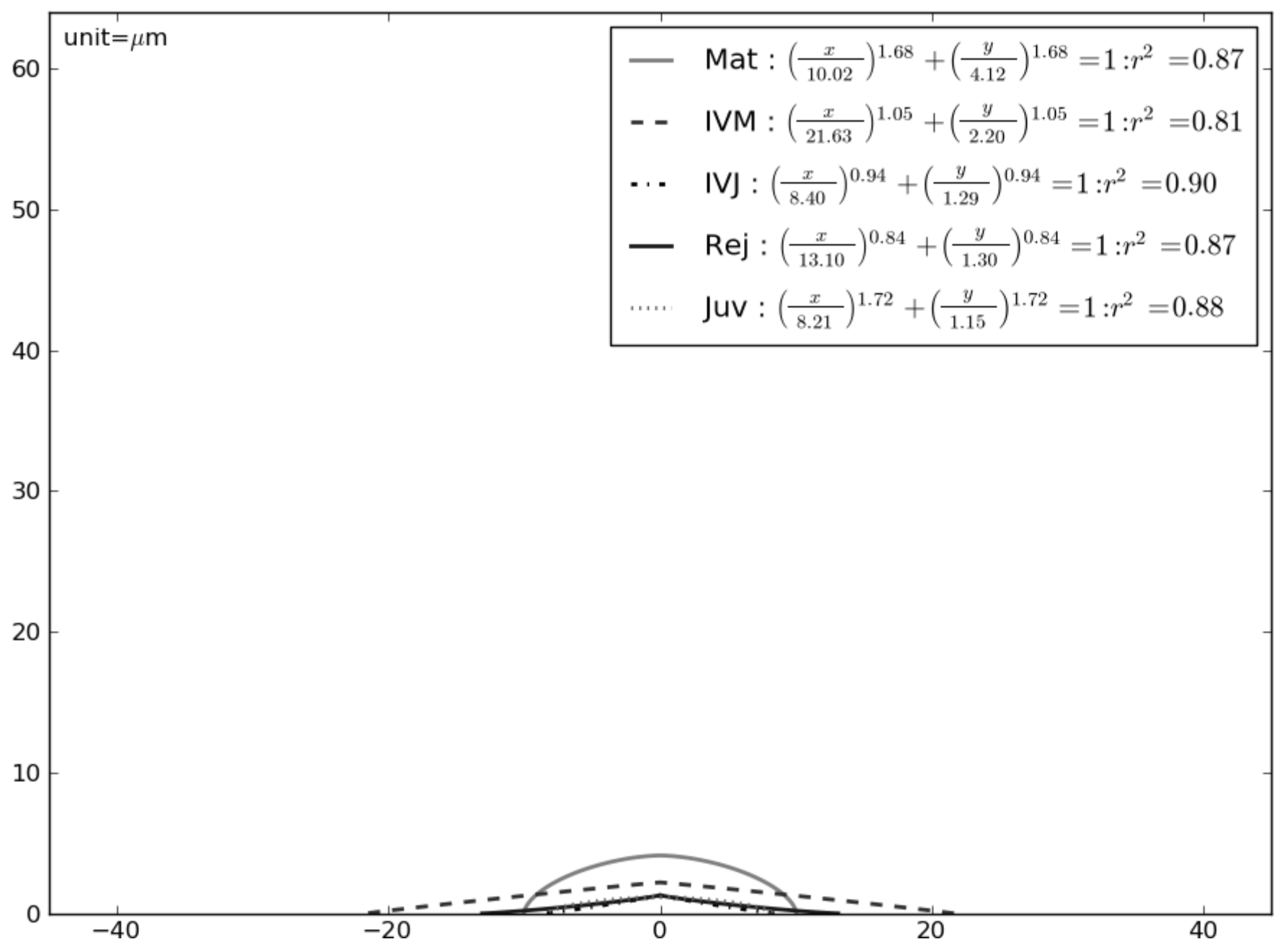

Fig. 11. Median estimated superellipse (sample size $9 \leq N \leq 21$ ) for the five origins of SAM assessed in $\mathrm{C} 2$ stage, with the associated equations and coefficients of determination $\left(r^{2}\right)$. 


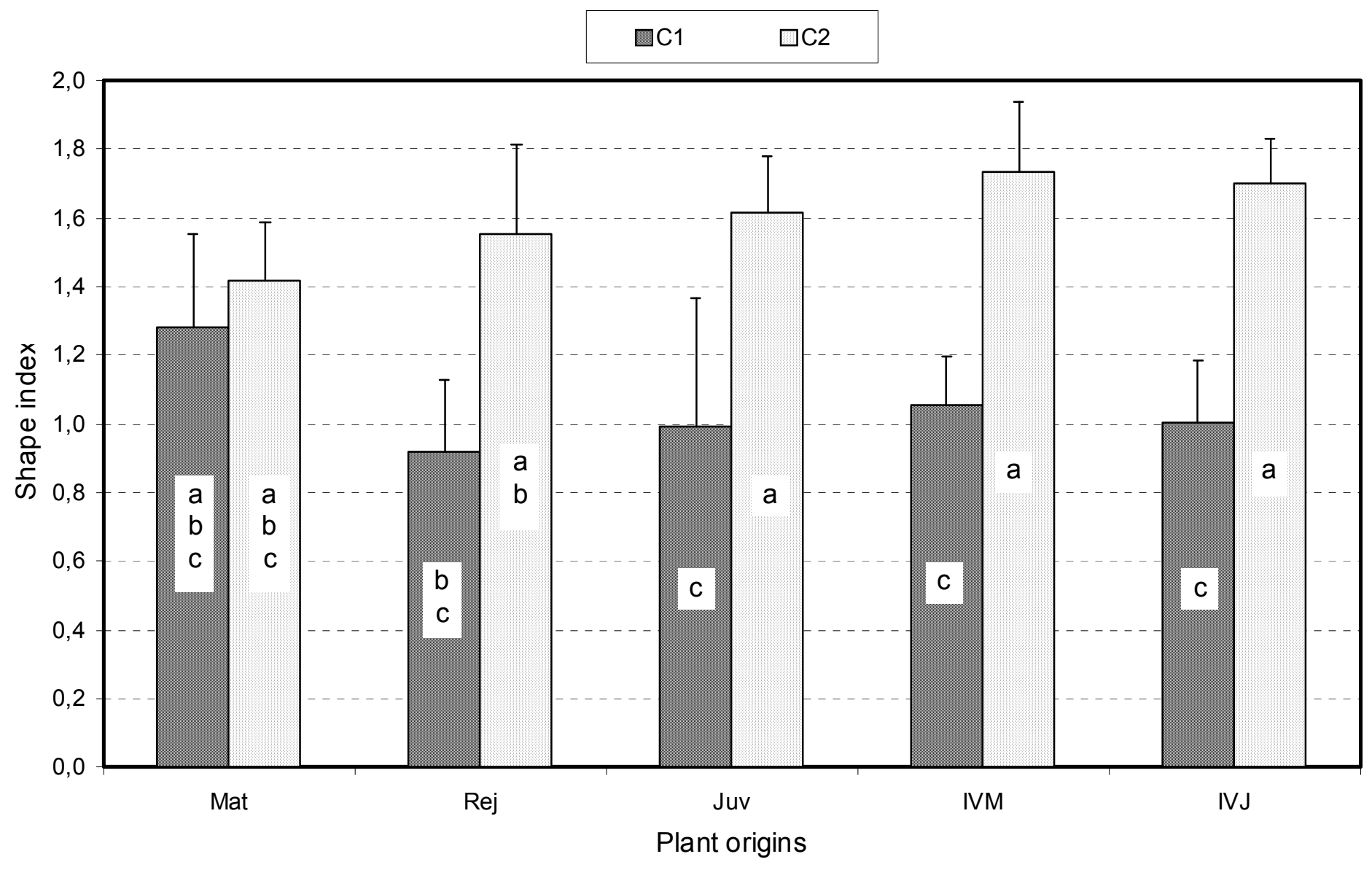

Fig. 12. Average SAM dome shape indices $S$ for the ten plant origin $x$ class combinations assessed with 9 to 21 observations per combination. Bars represent confidence intervals at Po $=5 \%$, and different letters distinguish means which are significantly different at the same $5 \%$ level (see text for further information). 